\title{
Lluita de classes i hegemonia a la ciutat tardofranquista i (proto)democràtica
}

Marc Andreu. 2015. Barris, veïns i democràcia. El moviment ciutadà i la reconstrucció de Barcelona (1968-1986). Barcelona: L’Avenç, 510 p.

\section{RICARD MARTÍNEZ I MUNTADA}

Universitat Autònoma de Barcelona / CEFID (Espanya) · orcid.org/0000-0002-0259-3888 http://dx.doi.org/10.7238/fit.voi4.3036

Fa ja uns quants anys, Xavier Domènech constatava que la història social del tardofranquisme i la Transició registrava un desplaçament d'interessos que centrava moltes mirades en el moviment veïnal, un objecte d'estudi que, llevat d'un cert nombre d'excepcions, havia estat poc atès per la recerca durant un llarg temps («Introducción. El movimiento vecinal y la historia social del antifranquismo», Historia del Presente 16, 2010: 5-7). Efectivament, aquest interès renovat el palesen diversos treballs, com ara el mateix dossier d'Historia del Presente que s'obria amb la reflexió esmentada -i que, a més, bevia en part de la recerca realitzada per al volum collectiu, publicat el mateix 2010 i coordinat per Carme Molinero i Pere Ysàs, Construint la ciutat democràtica (Barcelona: Icaria) - o les tesis doctorals d'Ivan Bordetas - «Nosotros somos los que hemos hecho esta ciudad». Autoorganización y movilización vecinal durante el tardofranquismo y el proceso de cambio político, UAB: 2012-, Marc Andreu -El moviment ciutadà i la transició a Barcelona: la FAVB (1972-1986), UB: 2014, en la qual es basa el llibre de què parlem-i José Miguel Cuesta -El moviment veïnal al Barcelonès Nord (1954-1987), UAB: 2014-; també cal esmentar la molt recent d'Eva Fernàndez Lamelas - Vocalies $i$ grups de dones: el feminisme als barris. El moviment de dones de base territorial durant la transició al cinturó industrial de Barcelona (1974-199o), UAB: 2016, una recerca antropològica amb una remarcable dimensió historiogràfica. Per bé que en altres llocs de l'Estat espanyol es desenvolupin treballs sobre el moviment veïnal, Catalunya és, amb diferència, el focus principal d'aquest esforç investigador.

Alguns d'aquests treballs han aconseguit sortir dels recintes acadèmics i han obtingut un ressò públic gens negligible. És el cas del de Marc Andreu, i ho illustra d'allò més bé el merescut Premi Ciutat de Barcelona 
d'història del 2015 a Barris, veïns i democràcia. És un reconeixement de l'obra per si mateixa, però també de l'extensa trajectòria de l'autor com a estudiós d'un moviment en el qual també ha estat profundament implicat com a activista i periodista. El seu primer treball sobre la qüestió, escrit a quatre mans amb l'enyorat Josep Maria Huertas Claveria, es remunta a fa ja dues dècades - Barcelona en lluita (El moviment urbà 1965-1996), Barcelona: FAVB, 1996. El més recent, publicat el 2016 Les ciutats invisibles. Viatge a la Catalunya metropolitana (Barcelona: L'Avenç)—, sense centrar-se pròpiament en el moviment veïnal, explora la realitat actual dels barris populars del nostre país, o dels territoris de les classes subalternes, per expressar-la en uns termes que potser connecten millor amb la mirada que ens suggereix Barris, veïns i democràcia.

El llibre que neix de la tesi de Marc Andreu reconstrueix i analitza l'experiència del moviment veïnal barceloní durant el tardofranquisme, la Transició i els primers anys de la democràcia, a través de l'estudi de la trajectòria del seu organisme de coordinació a escala de ciutat: la Federació d'Associacions de Veïns de Barcelona (FAVB). Es tracta d'una reconstrucció minuciosa, amb una riquíssima base documental, de fonts orals i bibliogràfica, afavorida per un coneixement de primera mà — diríem que íntim-, de l'objecte d'estudi; una proximitat que no perjudica, ans al contrari, el rigor científic de la recerca. L'obra presenta una estructura bàsicament cronològica, amb l'eix central de la progressiva apropiació d'una FAVB originàriament burgesa i d'ordre per les associacions combatives dels barris, en un procés complex en què es van combinar l'ocupació d'espais organitzatius, la política d'aliances i la conquesta de l'hegemonia. El capítol inicial se centra en el sorgiment, entre el 1968 i el 1974, d'un moviment veïnal reivindicatiu als barris populars de Barcelona, el qual es dotaria d'una primera articulació a escala de ciutat amb la formació de la semiclandestina Coordinadora de Sant Antoni (1972). El segon capítol presenta la constitució i l'estructuració de la FAVB (19721974) per les associacions «bombillaires», anomenades així perquè una part significativa dels seus esforços i pressupostos es destinaven a l'enllumenat nadalenc dels carrers. Ara bé, l'autor ens prevé contra la visió tòpica segons la qual es tractava de petits botiguers: en realitat, al darrere hi havia una poderosa burgesia comercial amb interessos al centre 
de la ciutat i connexions tant amb el règim com amb l'incipient pujolisme. El capítol més extens del llibre, el tercer, abasta el trienni clau de 1974-1976, que inclou l'entrada de les associacions de la Coordinadora de Sant Antoni a la FAVB i la progressiva conquesta d'espais i hegemonia en el seu si, traduïda en les posicions cada cop més combatives de la federació tant en el conflicte urbà com en el polític. Van ser també els temps de la pugna amb el governador civil i després ministre de Governació Rodolfo Martín Villa, de la lliuta al voltant de la revisió del Pla Comarcal i de les manifestacions per l'amnistia de febrer del 1976, en les quals la FAVB tingué un protagonisme central. El quart capítol, també de notable extensió, està dedicat a l'intens període 1977-1979, marcat per la pervivència d'un govern municipal no democràtic — franquista, en definitiva - que, tanmateix, va aplicar una part significativa de les propostes del moviment veïnal. Aquest moviment posseïa aleshores una alta capacitat de pressió, però, contradictòriament, també començava a mostrar els primers símptomes de crisi, una crisi relacionada amb el nou context protodemocràtic i amb l'emergència d'uns partits polítics que estrenaven legalitat, volien ocupar el seu espai i afirmaven -sobretot a partir de les eleccions del 15 de juny de 1977- la seva legitimitat en front del moviment. El darrer capítol, que arrenca de les eleccions municipals de l'abril del 1979 i arriba fins al 1986, resulta massa breu per aprofundir prou un període tan extens com complex, però ofereix pistes força útils per a futurs desenvolupaments, en especial pel que fa a la lluita de les associacions de veïns per la participació directa i a la resposta, a manera de bandejament - no exempt de menyspreu-, dels nous governants municipals d'esquerres (amb diferències importants entre un PSC molt dur i un PSUC més obert, encara que també fou criticat pels mateixos militants que van romandre al moviment, com ara Carles Prieto, president de la FAVB entre el 1978 i el 1982). Les conclusions refermen una de les hipòtesis centrals de la recerca, que postula que el projecte de transformació urbana formulat des del moviment veïnal —entès com a moviment de les classes subalternes - i l'esquerra antifranquista va esdevenir hegemònic en la Barcelona dels darrers anys de la dictadura. Aquesta hegemonia, articulada amb la massiva presència al carrer del veinat mobilitzat, va traduir-se en una intensa pressió sobre el poder mu- 
nicipal franquista i postfranquista, la qual comportà victòries polítiques importants i un impacte efectiu en la configuració de l'espai urbà. Sobre aquesta base, l'autor sosté que es pot afirmar que va haver-hi una «ruptura barcelonina», materialitzada, entre altres coses, en les destitucions dels alcaldes Porcioles (1973) i Viola (1976) i en les conquestes urbanístiques del moviment. Aquesta ruptura, a més, hauria estat «la llavor del consens urbà i de la forma de fer ciutat que després es coneixeria internacionalment com a model Barcelona» (p. 426).

Si la reconstrucció que ofereix el llibre és valuosa per si mateixa, també ho és la proposta interpretativa que aporta i que acabem d'esbossar a propòsit de les conclusions. Marc Andreu aborda el seu objecte d'estudi analitzant-lo sense embuts en clau de conflicte de classes - en les dimensions social, política i cultural-, una opció remarcable en uns temps en què una part no insignificant de la historiografia segueix errant enmig de boires postmodernes i, pel que fa a l'estudi interdisciplinari dels moviments socials urbans, continua essent punt de referència un Manuel Castells que, en la seva producció tardana sobre la qüestió, va fer contorsions impossibles per minimitzar la dimensió de classe que ell mateix havia elevat abans a la categoria d'única. (L'evidència que el nostre autor va a contracorrent del pensament dominant dins i fora de l'acadèmia es reflecteix, sense anar més lluny, en l'esgarrifada reacció de l'opinadora Patrícia Gabancho davant l'afirmació que fa el llibre de la centralitat obrera en el moviment veïnal. Vegeu «La construcció d'un mite», El País Catalunya, 24 jul. 2016, en què es combinen, a parts iguals, el classisme ranci i la ignorància històrica.) En realitat, com han mostrat una bona part dels estudis citats al començament, si el moviment veïnal no es pot explicar exclusivament en termes de lluita de classes - per exemple, cal incorporar-hi l'òptica de gènere-, resulta impossible entendre'l prescindint-ne. A més, l'autor posa en relleu que en el desenvolupament del conflicte urbà es van anar estenent propostes i valors que tendien a projectar un model alternatiu de ciutat, però també de societat, és a dir, que apuntaven a la superació del capitalisme. De fet, es tracta d'un fenomen que, en el curs de l'ascens de les mobilitzacions socials i polítiques dels darrers anys de la dictadura, es va produir no tan sols a Barcelona, sinó a tot Catalunya i arreu de l'Estat espanyol, i que cal emmarcar en l'onada de llui- 
tes i d'assajos de subversió de l'ordre vigent que durant els anys seixanta i setanta va recórrer el món sencer. Són encara escasses les recerques que han subratllat la presència i l'extensió d'elements politicoculturals tendencialment anticapitalistes en aquelles mobilitzacions del tardofranquisme. En el cas de Barcelona - i, de fet, de tota la regió metropolitana- aquesta presència va ser força intensa, i en aquest sentit l'aportació de Marc Andreu resulta molt pertinent. Ell no dubta a emprar el terme hegemonia per qualificar el pes i el suport que els projectes del moviment veïnal i de l'esquerra van assolir en la Barcelona d'aquells anys. Al meu entendre potser caldria una certa matisació, pel fet que es va tractar d'una hegemonia precària o de durada limitada, perquè la pugna no cessà mai i les correlacions de forces anaren canviant. En tot cas, aquest aspecte té un caràcter secundari: el fonamental, allò que cal reafirmar i recordar — com bé fa Marc Andreu-, és que aquelles propostes van esperançar amplis sectors de les classes subalternes, els quals, a més, veien que la seva lluita donava fruits. I és que també és molt pertinent el to que l'autor posa en les consecucions reals, materials - polítiques, socials i urbanes-, de l'acció del moviment; les victòries i conquestes obtingudes, en definitiva. Aquesta darrera constatació qüestiona les visions del procés de canvi polític que concedeixen tot el protagonisme a les elits i ignoren els efectes reals de l'acció dels moviments socials, però també les que interpreten la Transició com una desfeta sense palliatius de les classes subalternes.

Ara bé, també és cert que aquell impuls va anar decaient, que aquella hegemonia fou, en el millor dels casos, breu, i que aquelles expectatives de transformació urbana - i social - profunda no s'acompliren. En aquest sentit, voldria introduir alguna observació sobre aspectes de la interpretació que se'ns ofereix. Em sembla problemàtic atribuir una filiació gaire directa entre les lluites i formulacions urbanístiques del moviment veïnal i l'anomenat «model Barcelona», una idea que s'afirma en les conclusions i també en altres passatges del llibre. Més enllà del fet que, com ha indicat Horacio Capel, resulta difícil establir en què consisteix exactament l'esmentat model, el cert és que ni la ciutat actual, ni l'olímpica, ni tan sols la dels anys vuitanta - malgrat les innegables conquestes i millores aconseguides pels barris—, tenen gaire a veure amb l'«horitzó socialitzant» (p.19) dels plantejaments del moviment veïnal, dels quals només cal recordar 
la municipalització del sòl urbà per fer-se una idea de com en queda, de lluny, la ciutat realment construïda. Tal vegada la raó d'aquesta distància caldria buscar-la en el fet que potser no hi va haver, en sentit estricte, una «ruptura barcelonina». Que les propostes del moviment estiguessin a punt de ser hegemòniques o arribessin a ser-ho i que s'obtinguessin victòries importantíssimes, tant en l'àmbit urbà com en el polític, no significa que hi hagués ruptura. Podem parlar d'esdeveniments parcialment rupturistes - de microruptures, si volem-, però difícilment de ruptura en sentit rigorós. Barcelona no va ser una excepció en la continuïtat dels consistoris franquistes fins a l'abril del 1979 a causa del retard de les eleccions municipals imposat per Suárez, un fet relacionat amb la por que tenia la dreta d'un nou 12-14 d'abril de 1931 - Marc Andreu illustra a bastament aquesta qüestió-, però que, en tot cas, ajornà la democratització municipal a una data posterior a l'aprovació de la Constitució de 1978. Aquesta sí que fou, com assenyalà Tuñón de Lara, una «ruptura jurídica», encara que es tractés d'una discontinuïtat força allunyada de la ruptura somiada per l'antifranquisme més actiu. De tornada a Barcelona, tampoc no és irrellevant que el primer alcalde democràtic de la ciutat, elegit amb el suport de totes les forces provinents de l'antifranquisme, fos Narcís Serra, redactor a mitjan anys seixanta, amb el seu amic Miquel Roca Junyent, del projecte urbanístic del pla de la Ribera (p. 51). Loperació va ser aturada pel moviment veïnal i represa anys després, mutatis mutandis, arran de la metamorfosi de la ciutat per als Jocs Olímpics, com bé s'encarregaria de constatar en les seves memòries un cofoi Jordi Pujol — segons ens recorda Marc Andreu (p. 85). Durant els anys setanta, el moviment va aconseguir frenar la remodelació capitalista de Barcelona i imposà realitzacions urbanístiques i socials molt notables, però no va poder implantar-hi el seu model. Quan a la darreria de la dècada la seva força va minvar, el fre que havia representat començà a afluixar-se. Tot plegat no deixa de remetre'ns a les característiques i als límits de la Transició espanyola en conjunt, en particular a la canalització progressiva del procés de canvi cap a l'àmbit institucional i la pèrdua de protagonisme dels carrers. En aquest sentit, el moviment veïnal va patir una crisi derivada - encara que aquesta no en fos l'única causadel desplaçament envers les institucions de les prioritats dels principals partits de l'esquerra, per als quals els moviments socials van anar deixant 
de ser un ariet per fer caure el règim i van esdevenir un element de pressió per negociar en millors condicions (i, més endavant, si més no en àmbits com el municipal, fins i tot una nosa). L'obra mostra encertadament que aquesta crisi del moviment veïnal arrenca del 1977 i no de les municipals del 1979, i la relaciona, també encertadament, amb la qüestió de l'emergència i les noves prioritats dels partits; de tota manera, el lector queda amb les ganes de més sistematització interpretativa del tema, com també dels efectes específics de la retirada del que havia estat el partit hegemònic del moviment veïnal, el PSUC, a partir del 1977. Una retirada que no va respondre a consignes explícites ni va ser total, però que tingué un impacte innegable i que, malgrat els indicis de retorn al moviment que es mostren en algun passatge del llibre (p. 316), globalment no es capgirà mai més.

En qualsevol cas, aquestes darreres consideracions no són sinó modestos assajos de diàleg amb una obra que ha esdevingut una peça cabdal de la historiografia sobre el moviment veïnal. Una recerca que s'articula a la perfecció amb les altres produccions recents, ja que aporta una òptica fins ara inexistent i que era necessària després d'una sèrie de treballs predominantment dedicats a l'articulació de base del moviment des del punt de vista social, cultural, polític i associatiu. L'obra de Marc Andreu centra la mirada en allò que ara s'anomenaria organització de segon nivell, és a dir, de coordinació d'entitats de base, però sap eludir el risc que podria comportar fer una història «des de dalt» o estasiològica; ben al contrari, els barris i la textura del moviment real hi són sempre presents. En termes més generals, podem considerar acomplert el propòsit expressat en un fragment de la introducció en què l'autor reivindica la seva inspiració gramsciana: «escriure la història d'una organització significa, ni més ni menys, escriure la història general d'un país des d'un punt de vista monogràfic, per tal de posar-ne en relleu un aspecte característic» (p. 16). Efectivament, Barris, veïns $i$ democràcia constitueix una contribució rellevant a la història recent d'aquest país. A més, com que aquesta contribució es materialitza en la reconstrucció de l'experiència d'un moviment social que tingué un protagonisme central en els anys estudiats, és també un excellent exercici d'història «des de baix». 